\title{
Telégrafo, Televisão e Twitter: da alteração de percepção em McLuhan ao processo de midiatização
}

\section{Caroline Casali e Marco Bonito}

\section{Resumo}

Este artigo examina como Marshall McLuhan, ainda na década de 1960, não se restringe à estrutura midiática, mas aborda os meios de comunicação em relação à sociedade em que se inscrevem - indiciando a existência de processos midiáticos-, e aponta a massagem exercida por estes meios como responsável pela alteração nos processos de percepção e cognição - antecipando o que hoje entendemos por sociedade em vias de midiatização. Para tanto, revisitamos três momentos da comunicação: 1. A invenção do telégrafo e sua relação com a imprensa já estabelecida; 2. A televisão e a mudança de percepção nos telespectadores; e 3.0 Twitter em suas ferramentas como complexificação da massagem. Revisitamos os dois primeiros momentos, que são largamente refletidos pelo próprio McLuhan, em e, por fim, trabalhamos o Twitter relacionando apontamentos de McLuhan a conceitos contemporâneos que envolvem a midiatização.

\section{Palavras-Chave}

Processos midiáticos. Percepção. Cognição. Midiatização.

\section{Caroline Casali | carolcasali@gmail.com}

Doutoranda em Ciências da Comunicação pela Universidade do Vale do Rio dos Sinos - Unisinos. Professora Assistente do Departamento de Ciências da Comunicação do Centro de Educação Superior Norte - CESNORS/UFSM.

Marco Bonito I marcobonito@marcobonito.com.br Doutorando em Ciências da Comunicação pela Universidade do Vale do Rio dos Sinos - Unisinos. Professor Assistente do Campus de Ciências Humanas - Jornalismo - da Universidade Federal do Pampa - Unipampa.

\section{Considerações Iniciais}

A reflexão acerca da sociedade de massa vai dando lugar à análise de uma sociedade em vias de midiatização; a comunicação linear dos mass media é substituída pela discussão de processos midiáticos - portanto dinâmicos; e toda esta trajetória do pensamento comunicacional não soma 100 anos, idade que completaria em 2011 um dos pensadores de que nós, comunicadores e produtores de uma Ciência em Comunicação, devemos nos orgulhar, Marshall McLuhan. Cabe considerar que, enquanto as grandes teorias de que nos utilizamos para analisar objetos comunicacionais são derivadas de outras ciências e, portanto, pensadas para outros objetos que não a comunicação em si, McLuhan, justamente um dos precursores dos estudos em mídia, é ainda tomado pelo aforismo "o meio é a mensagem" e pouco explorado para o entendimento das lógicas contemporâneas da comunicação.

McLuhan é por vezes tratado como ultrapassado por ter se preocupado com os meios de comunicação de massa que, hoje, perdem espaço para a interatividade e comunicação colaborativa 
proporcionadas pela internet. Contudo, uma simples revisão de sua obra aponta para indícios de análise de uma sociedade que vai muito além da metade do século XX, onde se situam seus estudos. McLuhan, ainda que aponte a emergência das mídias sem falar em campos dos medias $^{1}$ ou processos midiáticos, antecipa a noção de processualidades e algumas dinâmicas de uma ambiência que hoje entendemos por midiatizada.

Nesse sentido, procuramos trabalhar aqui conceitos apontados por McLuhan e que cabem à sociedade em vias de midiatização. Para tanto, abordamos três momentos da comunicação; dois deles (que tratam de telégrafo e televisão) já foram discutidos por McLuhan nos capítulos "Telégrafo: o Hormônio Social" e "A Televisão: 0 Gigante Tímido", da obra Os Meios de Comunicação como Extensões do Homem publicada em 1996, e o terceiro momento abrange uma reflexão acerca do Twitter $^{2}$ como exemplo da potencialização das massagens exercidas pelos meios, e que levam ainda à constituição de uma sociedade em vias de midiatização. Optamos pela reflexão destes três momentos por considerarmos que são ilustrativos não apenas do desenvolvimento da indústria das mídias, mas também e principalmente da maneira como as interações com o meio e a partir do meio vêm modificando as experiências dos indivíduos em sociedade.

\section{Telégrafo e a superação da mensagem}

Desceu ao pátio, onde as árvores adensavam a sombra do crepúsculo, carregado de fuscas nuvens. E abria o portão, quando esbarrou com um rapaz que se esbaforia sobre a perna manca e gritava: - "É um telegrama!" Com que voracidade Iho arrancou das mãos! Correu à cozinha, ralhou desabridamente à Rosa pela falta de luz tardia! E, com um fósforo a arder os dedos, devorou, num lampejo, as linhas benditas: - 'Ministro aceita, tudo arranjado ...' 0 resto era o Cavaleiro lembrando que no domingo o esperava em Corinde, às onze, para almoçarem e conversarem [...] Gonçalo Mendes Ramires deu cinco tostões ao moço do telégrafo - galgou as escadas. Nas livraria, à claridade mais segura do candeeiro, releu 0 telegrama delicioso. Ministro aceita, tudo arranjado... (QUEIROZ, 2000, p. 206-207, grifos do autor). ${ }^{3}$

A cena descrita acima narra a emoção de um homem à espera de uma mensagem que chega via

Campo dos Media é a expressão que dá conta da instituição de mediação que se instaura na modernidade por conta da presença dos meios de comunicação na sociedade. Difere-se de mass media uma vez que esta expressão define unicamente 0 conjunto dos meios de comunicação social (RODRIGUES, 1997).

Twitter é uma rede social e servidor para microblogging, criado em 2006, e que permite aos seus usuários enviarem e receberem atualizações pessoais de seus contatos, em textos de até 140 caracteres, que são conhecidos como tweets.

A llustre Casa de Ramires é um romance realista da terceira fase do escritor português Eça de Queiroz. Publicado em 1900, narra a vida de Gonçalo Mendes Ramires, sua chegada à política e as tradições familiares portuguesas, em analogia com a própria história portuguesa, em suas mudanças políticas e tradições. 
telegrama. Esta cena é mais que literária, pois ilustra ocasiões cotidianas a partir do final do século XIX, quando telegramas eram esperados com ansiedade por serem portadores de mensagens urgentes, notícias que chegavam para mudar a vida de quem as recebiam. 0 telegrama valia, portanto, pela mensagem que portava e, desta forma, fazia do telégrafo nada mais do que um meio para transmiti-la.

McLuhan vai justamente além desta percepção dos interesses pessoais nas mensagens trocadas via telégrafo e aponta a tecnologia em seu uso como importante componente de uma "dimensão humana", sobre o que disserta especialmente no capítulo "Telégrafo: o Hormônio Social". Nele, a ideia de hormônio social é tomada para diferenciar a era mecânica de uma nova era que se formava a partir da eletricidade. Para McLuhan, a eletricidade encerraria as fases individuais e das funções especializadas que se davam na era mecânica, e o telégrafo marcava o início do meio de comunicação como projeção e extensão do sistema nervoso central humano, que se identificaria com a própria extensão da consciência. Seria como se os meios elétricos criassem uma espécie de interdependência orgânica entre as instituições da sociedade (e daí hormônio social) - como se fossem uma extensão de nosso sistema nervoso central -, enquanto que as tecnologias anteriores à eletricidade fossem extensões de alguma parte do corpo humano.

0 que caracteriza um mecanismo é a separação e a extensão de partes isoladas de nosso corpo - mão, braço, pés - em pena, martelo, roda. E a mecanização de uma função se efetua pela segmentação de cada fase de uma ação comum numa série de partes uniformes, repetíveis e móveis. 0 que caracteriza a cibernação (ou automação) é exatamente 0 oposto, pois é um processo que tem sido descrito como um meio de pensar e um meio de fazer. Em lugar de preocupar-se com máquinas separadas, a cibernação encara o problema da produção como um sistema integrado de manipulação da informação (MCLUHAN, 1996, p. 278).

\section{Esta interdependência orgânica de que}

fala McLuhan é ilustrada pela dinâmica do surgimento do telégrafo e sua apropriação pelos usuários e pela própria indústria das mídias. Assim como outras tecnologias, o telégrafo surge por investimentos estatais que, após terem definidos seus objetivos, são percebidos como lucrativos por empresas privadas e assim apropriados em sua comercialização. Contudo, os usos sociais empregados para tais ferramentas nunca são de todo previsíveis, 0 que para McLuhan significa dizer que "toda inovação não apenas provoca rupturas comerciais, mas também corrosões sociais e psicológicas" (MCLUHAN, 1996, p. 281).

Após o surgimento da linha telegráfica entre Washington e Baltimore, em 1844, usuários empreenderam jogos de xadrez entre peritos das duas cidades; as linhas telegráficas eram usadas ainda para jogos de loteria, mas a mudança realmente significativa para os midiólogos se dá justamente na percepção de que 0 telégrafo modificou a forma de fazer imprensa no início 
do século XX. É McLuhan quem aponta para estas transformações, quando diz que "com 0 telégrafo, deu-se uma revolução no método de captar e apresentar as notícias. Naturalmente, foram espetaculares os efeitos causados na linguagem, no estilo literário e nos assuntos" (MCLUHAN, 1996, p. 282).

Ora, ainda que não fale em processos midiáticos, portanto, 0 autor defende 0 caráter dinâmico do telégrafo e de sua apropriação, narrando a maneira pela qual as práticas telegráficas modificaram o fazer da imprensa a partir de 1848. Como exemplo desta mudança, McLuhan aponta a primeira correspondência de guerra, quando William Howard Russel transmitia via telégrafo ao The Times ${ }^{4}$ os horrores da vida militar britânica. As notícias chegavam via telégrafo ao jornal de maneira imediata e legitimando a "inclusiva dimensão do lado humano", este lado humano apontado por McLuhan como dimensão advinda das potencialidades da eletricidade.

A dimensão do 'lado humano' é simplesmente a do imediatismo da participação na experiência alheia e que ocorre com a informação imediata. As pessoas também se tornam instantâneas em suas respostas de compaixão ou furor, quando devem compartilhar com 0 todo da Humanidade a mesma extensão comum do sistema nervoso central (MCLUHAN, 1996, p. 284).
Esta dimensão humana de que fala McLuhan indicia já a noção de que os meios não existem por eles mesmos, mas fazem parte de um processo de apropriação social. 0 telégrafo não é mais apenas a mensagem que vai de um indivíduo a outro, que importava ao cotidiano particular, mas interessa, sobretudo, enquanto meio de comunicação que ultrapassa a importância da mensagem pra configurar-se em ferramenta de inclusão social - trata-se da extensão de um homem que não consegue por si só alcançar 0 imediato das notícias. 0 telégrafo é ferramenta e, ao mesmo tempo, constitui novas práticas.

Os jornais viram-se obrigados a organizaremse coletivamente para a captação de notícias a partir da existência do telégrafo e, desta forma, surge a Associated Press ${ }^{5}$ e 0 aumento no número de notícias veiculadas diminui a força das opiniões editoriais (MCLUHAN, 1996). Para 0 autor, 0 valor atribuído até então à imprensa mascarou a força das práticas telegráficas, que tornaram independentes de grandes veículos os jornais interioranos, por exemplo. E, ao acreditar que esta aceleração produzida pelos meios elétricos geraria a dissolução das organizações, McLuhan segue apontando indícios de uma sociedade (des)organizada por processos midiáticos, ainda que fixe seu discurso nos meios de comunicação. Exemplo disso é a ideia de que

The Times é um jornal britânico, editado e publicado diariamente em Londres desde 1785.

Associated Press é apontada como a mais antiga agência de notícias do mundo, tendo sido fundada em 1846 em caráter de cooperativa, nos Estados Unidos. 
os meios elétricos levariam antes a uma abolição da dimensão espacial do que a um afastamento das relações orgânicas.

A própria natureza do telefone, como de todos os meios elétricos, é a de comprimir e unificar 0 que antes era dividido e especializado. Só a 'autoridade do conhecimento' funciona por telefone, devido à velocidade que cria um campo total $\mathrm{e}$ inclusivo de relações. A velocidade exige que as decisões sejam inclusivas e não fragmentárias ou parciais; daí que os letrados - tipicamente resistam ao telefone. Mas o rádio e a TV, como veremos, possuem o mesmo poder de impor uma ordem inclusiva, como se fosse uma organização oral. No pólo oposto está a forma centro-margem das estruturas visuais e escritas da autoridade (MCLUHAN, 1996, p. 286).

Enfim, as práticas empreendidas a partir do telégrafo - e narradas e analisadas por McLuhan - apontam para um mundo não mais unificado por suas autoridades letradas, mas por uma comunicação mais imediata de continente a continente. Desta forma, percebemos que McLuhan, enquanto midiólogo, preocupou-se em analisar conjunturas, processos, ainda que tratasse especificamente do meio de comunicação enquanto objeto. Exemplo disto é a força que atribui ao telégrafo em superar a forma centro-margem das estruturas, deixando vir à tona uma comunicação mais inclusiva via processos midiáticos. Estes processos ganham outra forma - e mais poder - na presença da televisão, que altera a forma de percepção e cognição da sociedade pelas novas experiências que proporcionam ao telespectador.

\section{A Televisão e a alteração da percepção}

\begin{abstract}
Muitas vezes, assim, de noite, nos últimos tempos, como que tomado por uma embriaguez ruim, eu ligava a televisão e ficava vendo tudo 0 que passava sem pensar, não escolhia um programa em particular, olhava 0 que parecia, o movimento, a cintilação, a variedade. Não reparei, naquele momento, na deriva que estava tomando conta do meu comportamento [...] Uma das principais características da televisão quando ela está ligada é nos manter continuamente despertos de modo artificial (TOUSSAINT, 1997, p. 16). ${ }^{6}$
\end{abstract}

Parte literatura, parte narrativa de um cotidiano, o trecho acima ilustra diretamente a dimensão fria atribuída à televisão por McLuhan. 0 midiólogo salientou o traço paradoxal da televisão como meio frio, uma vez que ela envolve o público em uma profundidade móvel e comovente, mas que não o excita, agita ou revoluciona.

McLuhan trabalha com propriedade esta perturbação psíquica e social criada pela imagem da televisão e não por sua programação, no capítulo "A Televisão: 0 Gigante Tímido"

(MCLUHAN, 1996). Para ele, a televisão envolve 0 telespectador, mas não pode funcionar como pano de fundo, tal como o rádio se apresentava; seria necessário estar com a televisão para fazer parte de sua audiência, sua imagem exerce uma força subliminar. Exemplo desta qualidade tátil da 
imagem da TV seria, para McLuhan, os estudantes de Medicina que, em uma emissão de cirurgia em circuito fechado, afirmaram sentirem-se mais realizando a cirurgia do que a assistindo.

[...] a TV é um meio frio, participante. Quando aquecida por dramatizações e aguilhoadas, seu desempenho decresce, porque passa a oferecer menos oportunidade à participação. 0 rádio é um meio quente. Quando intensificado, seu desempenho é melhor. Não convida seus usuários ao mesmo grau de participação. 0 rádio pode servir de cortina sonora ou como controle do nível de ruído: é assim que 0 adolescente 0 utiliza para desfrutar de uma certa intimidade. A TV não funciona como pano de fundo. Ela envolve. É preciso estar com ela (MCLUHAN, 1996, p. 350).

Nesse sentido, para McLuhan, a força da imagem acaba por provocar baixo teor de informação, pois não se trata de uma tomada parada, como a fotografia, mas de uma provocação por impulsos luminosos. Daí decorre a crítica de McLuhan aos intelectuais que demonizavam a programação televisiva. Para o midiólogo, que acredita que 0 "meio é a mensagem" e, portanto, a fonte básica dos efeitos, há que se olhar para a existência da televisão em seu ambiente em vez de buscar controle sobre o seu conteúdo. McLuhan justifica tal poder do meio, e não do conteúdo veiculado nele em si, através de uma análise do surgimento do rádio e da TV na Europa e na América e na diferença de apropriação destes meios nas duas culturas, e afirma, portanto, que "é necessário suspender todos os julgamentos de valor no exame dos assuntos referentes aos meios, pois os seus efeitos nunca são isolados" (MCLUHAN, 1996, p. 354).
Ainda na década de 1960, McLuhan apontava para 0 equívoco em focar a preocupação no conteúdo televisivo quando na verdade o meio em si proporcionaria novas experiências e, portanto, novas percepções à sociedade. Para ele, "os cientistas políticos têm ignorado os efeitos dos meios em todos os tempos e lugares, simplesmente porque ninguém se dispõe a estudar os efeitos sociais e pessoais dos meios separadamente de seu conteúdo" (MCLUHAN, 1996, p.362-363), afinal o meio exerceria tamanha importância social pela interação que os usuários empreendiam com ele e não necessariamente pelo conteúdo - educativo ou deseducativo - que pudessem apresentar.

A experiência de uma pessoa é sempre superior à sua compreensão, e é a experiência, mais do que a compreensão, que influencia o comportamento, especialmente nas questões coletivas que dizem respeito aos meios e à tecnologia, de cujos efeitos, quase inevitavelmente, o indivíduo raramente se dá conta (MCLUHAN, 1996, p. 358).

Ora, se McLuhan aponta para a necessidade de perceber o meio em seus efeitos e não 0 conteúdo da programação televisiva, parece claro que ele já indicie a necessidade da própria substituição da análise dos meios em si pela análise de processos midiáticos. 0 midiólogo afirma que o objetivo de sua obra é antes "mostrar que nem a mais lúcida compreensão da força particular de um meio pode evitar o comum "fechamento" dos sentidos que nos conforma aos padrões da experiência apresentada" 
(MCLUHAN, 1996, p. 370). A experiência via TV ultrapassa, então, os objetivos do meio e a sociedade que se funda nesta nova percepção proposta pela televisão nunca mais poderá ser analisada simplesmente pela força do conteúdo, da programação dos meios. A percepção dos indivíduos se altera por meio de experiências televisivas, logo, alteram-se os próprios processos sociais, o que remete ao que chamamos hoje de sociedade em vias de midiatização. ${ }^{7}$

A TV mudou nossa vida sensória e nossos processos mentais. Criou um novo gosto por experiências em profundidade, que afeta tanto 0 ensino da língua como o desenho industrial dos carros. Com a TV, ninguém se contenta com um mero conhecimento livresco da poesia francesa ou inglesa. 0 clamor geral hoje é: 'Vamos falar francês' e 'É a vez e a voz do poeta' (MCLUHAN, 1996, p. 373).

Desta forma, para o midiólogo, não importaria a existência de um aparelho de televisão em cada sala de aula a partir de uma relação que se coloca entre meios de comunicação e sistemas de ensino. Importa, em contrapartida, saber o que a experiência com a televisão pode fazer com o ensino das disciplinas.

Nesse sentido, cabe entender que a televisão desenvolveu outras percepções e que, a partir disso, as demais experiências afetam-se pelo fazer televisivo. Esta ideia é muito bem ilustrada pela noção de que "em terra de cegos, quem tem um olho não é rei. Será antes um lunático alucinado", afinal "numa cultura altamente visual, é tão difícil comunicar propriedades não-visuais de formas espaciais como explicar a visualidade aos cegos" (MCLUHAN, 1996, p. 374).

Assim percebemos a tendência de McLuhan em ver a televisão como parte de um conjunto de meios, mas especialmente como um meio que afeta de forma diferente a experiência humana. E, por esta afetação, acaba modificando outras esferas sociais. Ele mesmo afirma que "poucas são as áreas de relações já estabelecidas - lar, igreja, escola, mercado - que não tenham sido profundamente afetadas em seu padrão e em sua tessitura" (MCLUHAN, 1996, p. 351).

Pois bem, ainda na década de 1960, 0 midiólogo adianta as próprias características de uma sociedade em vias de midiatização, ou seja, afetada pelas experiências proporcionadas pela vivência com os meios e através dos meios de comunicação. McLuhan, portanto, embora trabalhe os meios, não se fixa neles, mas trata das experiências e novas formas de percepção que se realizam a partir dos meios e por causa dos meios. Estas experiências são, enfim, potencializadas a partir da sinestesia proporcionada pela internet e por redes sociais como o Twitter. 


\section{Twitter e a massagem da produção-recepção}

Minha terra tem palmeiras/ Onde cantam os sabiás/ Mas aqui ninguém gorjeia/ Melhor que 0 Carpinejar (Daniel Piza).

Original, criativo, ousado, exagerado, visionário, cara de pau: se lhe faltam + adjetivos, unam-se sobrenomes e crie-se 0 verbo carpinejar (Abonico).

0 pio generoso alegra a sua corte digital. Uns milhares sortudos já viciados em tão fino alpiste... Toma aqui o teu! E, se piscar, tem mais (Fernanda Takai). ${ }^{8}$

As três frases acima citadas foram veiculadas na orelha do livro www.twitter.com/carpinejar, lançado em 2009 por Fabrício Carpinejar, escritor gaúcho, que produziu a obra baseado em frases já veiculadas em seu Twitter e intitulou o livro com seu próprio endereço no microblog. Os comentários respeitaram também os 140 caracteres máximos que cada publicação pode conter nesta rede social e caracterizam-se assim como a configuração do meio definindo a mensagem. Além disso, o Twitter representa uma sinestesia sequer pensada por McLuhan, ainda que ilustre muitas das preocupações que 0 midiólogo trazia em relação à aceleração das experiências midiáticas. Se o próprio McLuhan (1996, p. 278) já apontava, em 1964, que se vivia na Era da Informação e da Comunicação devido aos meios elétricos, que "[...] criam, instantânea e constantemente, um campo total de eventos interagentes do qual todos os homens participam", parece óbvio que hoje esta era tenha se intensificado, afinal a internet vem acelerando cotidinamente nossas experiências com e por meio das mídias. Eis que estamos consolidando a era apontada por McLuhan e dando a ela a inscrição de sociedade em vias de midiatização.

Em maio de 1966, após ter publicado Os Meios de Comunicação como Extensões do Homem, McLuhan proferiu em Nova Iorque uma conferência intitulada $O$ meio é $a$ massagem, em trocadilho a sua ideia de que 0 "meio é a mensagem". Nela, refletiu sobre os efeitos exercidos pelos mass media, que nos afetariam, segundo ele, porque nos massageiam, modificam nossa cognição, alteram nossa noção de espacialidade e temporalidade. Na ocasião, McLuhan (2005, p. 129) já dizia que "um ambiente é um processo, não é um invólucro", e, nesse sentido, os meios de comunicação alteram nossa relação com 0 ambiente porque mudam nossas perspectivas sensoriais. Se, para ele, quando uma nova mídia está em ação numa dada população, toda a vida sensorial das pessoas muda e, às vezes muda muito, "muda sua perspectiva, mudam suas atitudes, mudam seus sentimentos em relação aos estudos, à escola, à política" (MCLUHAN, 2005, p. 141). Entende-se que 0 midiólogo já se preocupa com a análise dos meios não por eles mesmos, mas principalmente pelo ambiente que se modifica pela alteração de percepção que os meios ocasionam. 
Nesse sentido, podemos inferir que existem, já na obra de McLuhan, indícios de uma preocupação com o que hoje denominamos sociedade em vias de midiatização - uma sociedade que empreende novas formas de cognição por meio das experiências midiáticas e que transita para estas experiências como processos interacionais de referência. É ao que Braga (2007) se refere como a sociedade que não apenas têm suas instituições (política, religiosa, escolar etc...) entrando nas lógicas das mídias, como ela mesma comporta-se, com um todo, em interações de midiatização.

Nossas preocupações atuais vão além dos meios, focando-se nas transformações de uma sociedade que domina o fazer dos mass media e, por isso, torna-se cada vez mais passível de percepções e experiências midiatizadas. Ora, o Twitter é exemplo típico de um novo ator midiático que é, ao mesmo tempo, produtor, editor e receptor. As postagens via Twitter caracterizam-se pelas ferramentas que 0 meio proporciona (postagem de links com fotos, vídeos, frases) e permitem que os usuários republiquem textos de outros membros da rede, repliquem estes textos e opinem sobre eles.

A noção de agricultor e caçador a que McLuhan se refere na Conferência vem a calhar quando tratamos deste novo receptor-produtor midiático, que se preocupa, tal como o caçador, em coletar, classificar e não necessariamente em plantar, como o faz 0 agricultor. 0 twiteiro é também um caçador em busca de bons produtos para classificar e reproduzir, compondo também o texto, fazendo parte de sua produção na medida em que contribui em sua veiculação. Em midiatização, as informações circulam e nos chegam o tempo todo e, assim, nos tornamos caçadores das coisas que elegemos como prioritárias, que constituem nosso gosto, enfim, que fazem parte do nosso 'estilo' e que nos definem como artistas desse novo fazer no dominar os rituais midiáticos e reproduzi-los. 0 Twitter se configura como a complexificação das mídias de massa, que permite a cada usuário ter seu próprio canal, sua própria audiência e transmitir instantaneamente suas mensagens a um público cada vez maior e mais distinto.

Percebemos, assim, o quanto os meios não são apenas mensagens, mas mensagens a nos massagear. Contudo, estas novas experiências que derivam do domínio do fazer dos mass media, não são simples operações, mas protocolos complexos. Se antes poderíamos ser classificados pelo nosso ethos, hoje assumimos várias identidades; nossos papéis se complexificam porque experimentamos outras formas de percepção e ação. 0 limite de 140 caracteres para cada postagem no Twitter, por exemplo, é constantemente burlado por novas tecnologias que vão sendo incorporadas, como 0 encurtador de links. ${ }^{9}$ Portanto, não temos como problema - e McLuhan já estava ciente disso - os instrumentos midiáticos, mas nossa problemática maior é sim, antes, de inteligência e cognição. 0 midiólogo nos traz a ideia de que a estrutura 
apenas tipifica os objetos de uma área, de um campo, mas estes objetos são dinamizados em um ambiente, por meio de processos.

\section{Em vias de conclusão}

São os processos que atualizam os objetos e McLuhan, ainda que falasse sobre meios, entendia isso. Os objetos constituídos pelos campos só podem ser aclarados quando dinamizados em práticas, logo é sobre estas práticas que nós, pesquisadores de Comunicação, devemos nos debruçar. McLuhan o fez quando analisou o telégrafo para além da mensagem, em um circuito de modificação da imprensa - como extensão da própria experiência humana; também o fez quando refletiu sobre a maneira como a televisão afetou a percepção e a cognição do telespectador, através de novas experiências, intensificando, desta forma, um processo que hoje entendemos por sociedade em vias de midiatização.

McLuhan apontou várias questões que retratam a interação entre meios de comunicação e sociedade e que remontam à midiatização. As massagens não são hoje funções específicas dos meios, mas também práticas do que antes se entendia por recepção - e o Twitter está aí como exemplo disso. As redes sociais exigiram uma proatividade por parte dos seus atores que extrapolaram a simples função mediadora de outrora, permitindo que o meio seja reconfigurado a partir dos chamados aplicativos que podem ser incorporados ao sistema conforme 0 interesse do texto. Enfim, apenas recentemente, a internet é responsável pela reconfiguração dos papéis de produtor e receptor, contudo, muitas das questões ao entorno desta reconfiguração, como processo que deriva da alteração de percepção e de cognição de uma sociedade em contato com os meios, foram, ainda na década de 1960, apontadas por McLuhan - a quem as Ciências da Comunicação deve muito.

\section{Referências}

BRAGA, J. L. Mediatização como processo interacional de referência. In: MÉDOLA, A.; CORREA ARAÚJO, D.; BRUNO, F. (Org.). Imagem, visibilidade e cultura midiática. Porto Alegre: Sulina, 2007.

CARPINEJAR, fabrício. www.twitter.com/carpinejar. Rio de Janeiro: Bertrand Brasil, 2009.

\section{MCLUHAN, M. Os meios de comunicação como} extensões do homem. 8.ed. São Paulo: Cultrix, 1996. MCLUHAN, M. 0 meio é a massagem. In: McLuhan por McLuhan: conferências e entrevistas. Rio de Janeiro: Ediouro, 2005. p.113-142.

QUEIROZ, Eça de. A Ilustre Casa de Ramires. São Paulo: Ateliê Editorial, 2000.

RODRIGUES, Adriano. Estratégias da comunicação. Lisboa: Presença, 1997.

TOUSSAINT, Jean-Philippe. A televisão. São Paulo: Editora 34, 1999. 
Telegraph, Television and Twitter: from the altering of perception in McLuhan to the mediatization process

\section{Abstract}

This paper examines how Marshall McLuhan, in the 1960 's, does not restrict himself to the mediatic framework, but approaches the media in relation to the society in which they are inscribed - indicating the existence of mediatic processes -, and assigns the message exerted by such media as the one responsible for the alteration in the perception and cognition processes _ anticipating that which today we understand as society in the process of mediatization. For that purpose, we have revisited three moments of communication: 1. The invention of the telegraph and its relationship with the already established print; 2. Television and the change in the viewers' perception; and 3. Twitter in its tools as a complexification of the message. We revisited the first two moments, which are broadly reflected by McLuhan himself, in Understanding Media: The Extensions of Man and, finally, we work on Twitter establishing a relationship between McLuhan's notes and contemporary concepts which involve mediatization.

\section{Keywords}

Mediatic Processes. Perception. Cognition. Mediatization.
Telégrafo, Televisión, y Twitter: desde el cambio de percepción en McLuhan a el proceso de mediatización

\section{Resumen}

Este artículo examina cómo Marshall McLuhan, incluso en los años 1960, no se limita a la estructura de los medios de comunicación, pero las direcciones de los medios de comunicación en relación con la sociedad - lo que indica la existencia de procesos de los medios de comunicación - y habla de las masajes ejercida por estos medios de comunicación como responsables de los cambios en los procesos de percepción y la cognición - anticipando lo que hoy entendemos por sociedad en lo proceso de la mediatización. Con este fin, revisamos tres momentos de la comunicación: 1. La invención del telégrafo y su relación com a prensa estabelecida; 2. La televisión y el cambio de percepción en el público; y 3 . Twitter como una herramienta en su complejidad de la masaje. Revisamos los dos primeros momentos, que se reflejó en gran medida por el de McLuhan, em "Los medios como extensiones del hombre" y, finalmente, nos trabajamos sobre el Twitter, refletindo sobre conceptos del McLuhan in relación a mediatización y sus conceptos contemporáneos.

\section{Palabras Clave}

Procesos de los medios de comunicación. Percepción. Cognición. Mediatización. 


\section{Expediente}

A revista E-Compós é a publicação científica em formato eletrônico da Associação Nacional dos Programas de Pós-Graduação em Comunicação (Compós). Lançada em 2004, tem como principal finalidade difundir a produção acadêmica de pesquisadores da área de Comunicação, inseridos em instituições do Brasil e do exterior.
E-COMPÓS I www.e-compos.org.br I E-ISSN 1808-2599

Revista da Associação Nacional dos Programas

de Pós-Graduação em Comunicação.

Brasília, v.14, n.3, set./dez. 2011.

A identificação das edições, a partir de 2008

passa a ser volume anual com três números.
CONSELHO EDITORIAL

Afonso Albuquerque, Universidade Federal Fluminense, Brasil Alberto Carlos Augusto Klein, Universidade Estadual de Londrina, Brasil Alex Fernando Teixeira Primo, Universidade Federal do Rio Grande do Sul, Brasil Ana Carolina Damboriarena Escosteguy, Pontifícia Universidade Católica do Rio Grande do Sul, Brasil

Ana Gruszynski, Universidade Federal do Rio Grande do Sul, Brasil Ana Silvia Lopes Davi Médola, Universidade Estadual Paulista, Brasil André Luiz Martins Lemos, Universidade Federal da Bahia, Brasil Ângela Freire Prysthon, Universidade Federal de Pernambuco, Brasil Angela Cristina Salgueiro Marques, Faculdade Cásper Líbero (São Paulo), Brasil Antônio Fausto Neto, Universidade do Vale do Rio dos Sinos, Brasil Antonio Carlos Hohlfeldt, Pontifícia Universidade Católica do Rio Grande do Sul, Brasil Antonio Roberto Chiachiri Filho, Faculdade Cásper Líbero, Brasil Arlindo Ribeiro Machado, Universidade de São Paulo, Brasil Arthur Autran Franco de Sá Neto, Universidade Federal de São Carlos, Brasil Benjamim Picado, Universidade Federal Fluminense, Brasil César Geraldo Guimarães, Universidade Federal de Minas Gerais, Brasil Cristiane Freitas Gutfreind, Pontifícia Universidade Católica do Rio Grande do Sul, Brasil Denilson Lopes, Universidade Federal do Rio de Janeiro, Brasil Denize Correa Araujo, Universidade Tuiuti do Paraná, Brasil Edilson Cazeloto, Universidade Paulista , Brasil Eduardo Peñuela Cañizal, Universidade Paulista, Brasil Eduardo Vicente, Universidade de São Paulo, Brasil Eneus Trindade, Universidade de São Paulo, Brasil Erick Felinto de Oliveira, Universidade do Estado do Rio de Janeiro, Brasil Florence Dravet, Universidade Católica de Brasília, Brasil Francisco Eduardo Menezes Martins, Universidade Tuiuti do Paraná, Brasi Gelson Santana, Universidade Anhembi/Morumbi, Brasil Gilson Vieira Monteiro, Universidade Federal do Amazonas, Brasil Gislene da Silva, Universidade Federal de Santa Catarina, Brasil Guillermo Orozco Gómez, Universidad de Guadalajara Gustavo Daudt Fischer, Universidade do Vale do Rio dos Sinos, Brasil Hector Ospina, Universidad de Manizales, Colômbia Herom Vargas, Universidade Municipal de São Caetano do Sul, Brasil leda Tucherman, Universidade Federal do Rio de Janeiro, Brasi Inês Vitorino, Universidade Federal do Ceará, Brasil Janice Caiafa, Universidade Federal do Rio de Janeiro, Brasi Jay David Bolter, Georgia Institute of Technology Jeder Silveira Janotti Junior, Universidade Federal de Pernambuco, Brasil João Freire Filho, Universidade Federal do Rio de Janeiro, Brasi John DH Downing, University of Texas at Austin, Estados Unido José Afonso da Silva Junior, Universidade Federal de Pernambuco, Brasil
José Carlos Rodrigues, Pontifícia Universidade Católica do Rio de Janeiro, Brasil José Luiz Aidar Prado, Pontifícia Universidade Católica de São Paulo, Brasil José Luiz Warren Jardim Gomes Braga, Universidade do Vale do Rio dos Sinos, Brasi Juremir Machado da Silva, Pontifícia Universidade Católica do Rio Grande do Sul, Brasil Laan Mendes Barros, Universidade Metodista de São Paulo, Brasil Lance Strate, Fordham University, USA, Estados Unidos Lorraine Leu, University of Bristol, Grã-Bretanha Lucia Leão, Pontifícia Universidade Católica de São Paulo, Brasil Luciana Panke, Universidade Federal do Paraná, Brasil Luiz Claudio Martino, Universidade de Brasília, Brasil Malena Segura Contrera, Universidade Paulista, Brasi Márcio de Vasconcellos Serelle, Pontifícia Universidade Católica de Minas Gerais, Brasil Maria Aparecida Baccega, Universidade de São Paulo e Escola Superior de Propaganda e Marketing, Brasil

Maria das Graças Pinto Coelho, Universidade Federal do Rio Grande do Norte, Brasil Maria Immacolata Vassallo de Lopes, Universidade de São Paulo, Brasil Maria Luiza Martins de Mendonça, Universidade Federal de Goiás, Brasil Mauro de Souza Ventura, Universidade Estadual Paulista, Brasil Mauro Pereira Porto, Tulane University, Estados Unidos

Nilda Aparecida Jacks, Universidade Federal do Rio Grande do Sul, Brasil Paulo Roberto Gibaldi Vaz, Universidade Federal do Rio de Janeiro, Brasil Potiguara Mendes Silveira Jr, Universidade Federal de Juiz de Fora, Brasil Renato Cordeiro Gomes, Pontifícia Universidade Católica do Rio de Janeiro, Brasil Robert K Logan, University of Toronto, Canadá

Ronaldo George Helal, Universidade do Estado do Rio de Janeiro, Brasil Rosana de Lima Soares, Universidade de São Paulo, Brasil Rose Melo Rocha, Escola Superior de Propaganda e Marketing, Brasil Rossana Reguillo, Instituto de Estudos Superiores do Ocidente, Mexico Rousiley Celi Moreira Maia, Universidade Federal de Minas Gerais, Brasil Sebastião Carlos de Morais Squirra, Universidade Metodista de São Paulo, Brasil Sebastião Guilherme Albano da Costa, Universidade Federal do Rio Grande do Norte, Brasil

Simone Maria Andrade Pereira de Sá, Universidade Federal Fluminense, Brasil Tiago Quiroga Fausto Neto, Universidade de Brasília, Brasil Suzete Venturelli, Universidade de Brasília, Brasil Valério Cruz Brittos, Universidade do Vale do Rio dos Sinos, Brasil Valerio Fuenzalida Fernández, Puc-Chile, Chile

Veneza Mayora Ronsini, Universidade Federal de Santa Maria, Brasil Vera Regina Veiga França, Universidade Federal de Minas Gerais, Brasil Valerio Fuenzalida Fernández, Puc-Chile, Chile Veneza Mayora Ronsini, Universidade Federal de Santa Maria, Brasil Vera Regina Veiga França, Universidade Federal de Minas Gerais, Brasil

\section{COMISSÃO EDITORIAL}

Adriana Braga I Pontifícia Universidade Católica do Rio de Janeiro, Brasil Felipe Costa Trotta I Universidade Federal de Pernambuco, Brasil

CONSULTORES AD HOC

Édison Gastaldo, Universidade Federal Rural do Rio de Janeiro, Brasil

EDIÇÃO DE TEXTO E RESUMOS I Susane Barros

SECRETÁRIA EXECUTIVA I Juliana Depiné

EDITORAÇão ELETRÔNICA I Roka Estúdio

TRADUÇÃO I Sieni Campos e Robert Finnegan
COMPós I www.compos.org.br

Associação Nacional dos Programas de Pós-Graduação em Comunicação

Presidente

Julio Pinto

Pontifícia Universidade Católica de Minas Gerais, Brasil

juliopinto@pucminas.br

Vice-presidente

Itania Maria Mota Gomes

Universidade Federal da Bahia, Brasil

itania@ufba.br

Secretária-Geral

Inês Vitorino

Universidade Federal do Ceará, Brasil

inesvict@gmail.com 